\title{
LA INTIMIDAD EN EL CINE DE NO FICCIÓN: UN'ORA SOLA TI VORREI, DE ALINA MARAZZI ${ }^{1}$
}

\author{
INTIMACY/PRIVACY/INTIMATE IN NON-FICTION FILM: \\ ALINA MARAZZI'S UN'ORA SOLA TI VORREI
}

\section{María de la Paz CEPEDELLO MORENO}

Universidad de Córdoba fe2cemom@uco.es

Resumen: El documental ha experimentado, desde finales del siglo XX, un significativo giro subjetivo y se ha erigido como un espacio idóneo para la experimentación narrativa y visual con el objetivo de dar cuenta de la intimidad. A partir de esta premisa, pretendemos demostrar que este giro supone la puesta en escena de un yo que construye un relato alrededor de sí y que, además, en el caso del discurso fílmico construido por cineastas mujeres este sífemenino tiene características peculiares.

Palabras clave: Intimidad. Autobiografía. Documental. Marazzi.

Abstract: Documentaries have experienced, since the late Twentieth Century, an important subjunctive change becoming a perfect space for the narrative and visual experimentation in order to show intimacy. From this premise, we want to demonstrate that this change has an evident consequence: there is a new me which builds a story around itself and that, besides, in the case of the film speech built by women, this (her) self has

\footnotetext{
${ }^{1}$ Este artículo se inscribe en el marco del proyecto de investigación franco-español "Figures et frontières de l'intime à l'époque contemporaine / Figuras y fronteras de la intimidad en la época contemporánea" (OPE-2017-0042), Universidad de Pau et des Pays de l>Adour EFM (FR 4153), ALTER (EA7504), ITEM (EA 3002) en colaboración con el grupo de investigación «Lenguajes» (HUM 224) de la Universidad de Córdoba (España) y el laboratorio "Arts Plastiques" (EA 7472) de la Universidad de Rennes 2 (Francia).
} 
special features to take into account.

Key Words: Intimacy. Autobiography. Documentary. Marazzi.

\title{
1. INTRODUCCIÓN
}

El cine, desde sus orígenes, está vinculado al relato de la vida privada. Baste recordar, para demostrarlo, la presentación comercial del cinematógrafo que tuvo lugar en París el 28 de diciembre de 1895. Entre las diez producciones que se exhibieron en el Salon Indien du Grand Café, todas ellas de los hermanos Lumière ${ }^{2}$, se encontraba Le Repas de bébé: un plano secuencia, en encuadre fijo, de 41 segundos, donde puede verse al matrimonio Lumière, Auguste y Marguerite, dando de comer a su hija Andrèe (figura 1).

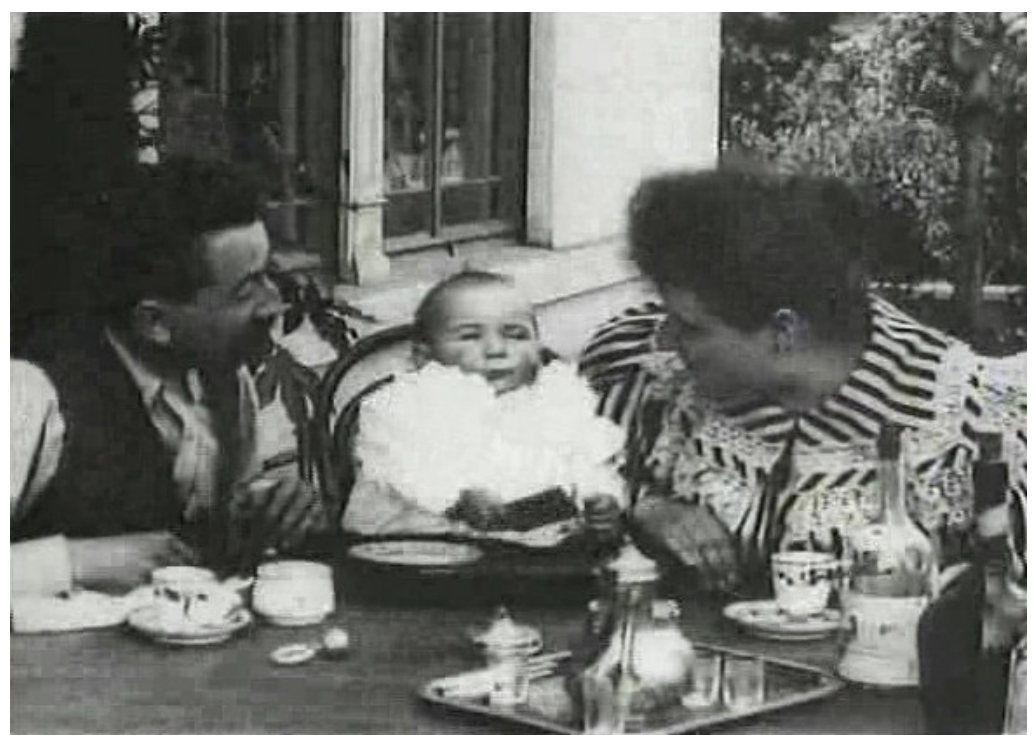

Figura 1. Le Repas de bébé

\begin{abstract}
${ }^{2}$ Los títulos de las diez películas que se proyectaron en aquella presentación del cinematógrafo según aparecen en el programa original son: La Sortie de l'usine Lumière à Lyon, La Voltige, La Pêche aux Poissons Rouges, Le Débarquement du Congrès du Photographie à Lyon, Les Forgerons, Le Jardinier, Le Repas, Le Saut à la Couverture, La Place des Cordeliers à Lyon y La Mer.
\end{abstract}


Estudiosos como Paola Lagos (2011: 62) opinan que este corto bien puede considerarse la primera película casera de la historia del cine y el punto de partida de un largo camino donde son constantes los entrecruzamientos entre la narración fílmica autobiográfica y el cine doméstico familiar. Precisamente nos interesa en este trabajo, entre otros aspectos, esa capacidad de las películas caseras, como veremos en Marazzi, para captar los acontecimientos más o menos trascendentes de la vida cotidiana desde una mirada abiertamente subjetiva en una doble dirección: la del que mira los acontecimientos a través del objetivo y los registra, mientras los está viviendo, y la de los que están siendo filmados y se saben protagonistas de una película que capta sus vidas en estado puro. No obstante, antes de avanzar en la consideración de Un'ora sola ti vorrei como una auto-bio-grafía cinematográfica es preciso perfilar los límites de lo que consideramos tal manifestación y qué rasgos la caracterizan en tanto discurso fílmico diferenciado.

\section{CINE Y AUTOBIOGRAFÍA}

Abordar el estudio de un género como la autobiografía fílmica que, todavía hoy, presenta problemas de delimitación resulta un reto especialmente complicado si para ello consideramos propuestas como la que ofrece la realizadora italiana en la medida en que pretendemos dilucidar el lugar que ocupa dentro de las siempre difusas fronteras de los subgéneros cinematográficos yoicos.

Los estudios sobre el cine autobiográfico, en sus diferentes manifestaciones, comienzan a aparecer pocos años después del extraordinario desarrollo que tuvieron en el último cuarto del siglo XX las propuestas teóricas sobre los discursos escritos del yo que pretendían dar cuenta de la singularidad compositiva y argumental, así como del funcionamiento pragmático, de unos textos escasamente considerados hasta ese momento. Como recuerda A. G. Loureiro (1991), estas propuestas se habían desarrollado, fundamentalmente, bajo el paraguas de tres paradigmas teóricos diferenciados, a saber, la pragmática, la deconstrucción y la teoría feminista.

La primera línea, representada por el padre de los estudios autobiográficos en Europa, P. Lejeune, parte del valor cognoscitivo 
de la autobiografía. Desde la aparición del archiconocido Le pacte autobiographique (1975) el teórico francés ha sometido a revisión prácticamente la totalidad de las ideas expuesta en su obra (1980, 1986, 2001, 2004, 2015), pero, en lo esencial, mantiene que lo que caracteriza la autobiografía es la identidad entre autor, narrador y personaje, que es lo que constituye el "pacto autobiográfico" y que no deja de ser un contrato de lectura entre autor y lector que deja en manos de este último la capacidad de unificar la identidad de las tres figuras mencionadas.

Dentro del texto, así lo señala Nora Catelli (1991) al analizar la teoría de Lejeune, narrador y personaje son definidos lingüísticamente como sujetos de la enunciación y del enunciado respectivamente. Y el nombre propio, que es el referente, es aquello a lo que remite el sujeto de la enunciación. He aquí el rasgo más diferenciador, a juicio del estudioso francés, de la autobiografía: el sujeto de la enunciación remite a algo fuera del texto, a diferencia del resto de los relatos en prosa. Así pues, la relación entre el autor y el enunciador autobiográfico no se rige según las pautas de la comunicación ficcional y entre ambos no cabe establecer una identidad exacta, sino que cabría hablarse, como señala Fernando Cabo (1993: 136), de una voluntad de identificación pragmática. A esto hemos de añadir el cuarto elemento para que exista lo autobiográfico: la dimensión mítica del yo individual, la expansión de la subjetividad. No jugamos pues en la autobiografía con el concepto de verosimilitud ni con el efecto de lo real sino con la imagen misma de lo real ${ }^{3}$.

La segunda línea teórica en la investigación sobre el género que nos ocupa está representada por los trabajos de Paul de Man, quien concibe la

\footnotetext{
${ }^{3}$ Las propuestas de Lejeune han sido sometidas a numerosas críticas, rectificaciones, como las del propio autor (véase Lejeune, 2004), y rotundas negaciones entre las que destacan la de los deconstruccionistas. Sin embargo, no han faltado mentes preclaras que han sabido aprovechar las innegables aportaciones del francés para hacerlas conjugar con otras perspectivas teóricas que venían a enriquecer la caracterización del estatuto autobiográfico. En este sentido Darío Villanueva (1993: 22), que vislumbró con claridad los problemas que atañían al yo autobiográfico, concluye que "la autobiografía como género literario posee una virtualidad creativa, más que referencial. Virtualidad de poiesis antes que de mimesis. Es, por ello, un instrumento fundamental no tanto para la reproducción cuanto para una verdadera construcción de la identidad del yo". En la misma línea, Castilla del Pino (1989: 47) en su triple condición de psiquiatra, autobiógrafo y analista del hecho literario considera que uno de los principales propósitos de las autobiografías es la de construirse, trasladándose de la posición de sujeto a la de objeto para sí y para los demás porque "el objeto que se exhibe es la identidad que previamente se ha construido en la escritura".
} 
prosopopeya como la figura esencial de la autobiografía y en virtud de ella cumple su función de dar voz a los ausentes generando en el texto en el que entra en actuación una retórica performativa. De ello de Man (1991: 113118) deduce que la vida no es la que produce el texto autobiográfico en un proceso mimético, sino que es la idea de mímesis la que produce la ilusión referencial. En resumidas cuentas, si la autobiografía supone la realización de un tropo - la prosopopeya-, se hace imposible el conocimiento científico del lenguaje y, en consecuencia, el conocimiento científico de la escritura del yo. Parece que de Man olvida que "la verdad autobiográfica no es identificable con la exactitud, sino con la verdad moral, es decir, la actitud del autobiógrafo de decir verdad" (Castilla del Pino, 2004: 25).

La tercera línea teórica, de raíz feminista, está integrada por los trabajos de Shari Benstock o Susan Friedman, por citar un par de nombres bien conocidos y reconocidos. Pero resulta especialmente interesante para este estudio, las aportaciones de Sidonie Smith (1987) quien, como las feministas francesas, parte del psicoanálisis para encontrar ese lugar específico que un discurso de mujer autobiográfico tiene y que la teoría representada por Freud y más adelante por Lacan le niega.

Tradicionalmente, la autobiografía se ha revelado como un género que mantenía las estructuras falocéntricas del discurso literario. La irrupción de la mujer en el texto autobiográfico, según Smith, es paralela a la alteración de la tradición masculina por el texto de la mujer. En este sentido se puede observar una clara diferencia entre los discursos femeninos previos al siglo XX y los nacidos en este siglo. En los primeros, las mujeres que decidían escribir su vida debían aceptar un contrato patriarcal por el cual debían justificar su presencia en la parcela de lo público. Era necesario explicar la apropiación ilegítima de un mundo, el masculino, al que tradicional y patriarcalmente han pertenecido las palabras, los signos, los símbolos. En los textos del siglo XX, las autobiógrafas empiezan a tomar conciencia de su identidad como mujer en la cultura patriarcal. Son capaces de reconocer la mutilación intangible a la que han sido sometidas en todas las parcelas de la vida y reclaman su derecho al deseo y la identidad propia.

Todas estas ideas de la investigadora feminista no le impiden estar de acuerdo con otras apreciaciones más canónicas de la teoría autobiográfica. Así, Smith asume el género como acto del presente de la escritura que da sentido al pasado, la idea del pacto autobiográfico o la hipótesis de que el lector de un texto autobiográfico espera una verdad de 
algún tipo. Pero tampoco renuncia a la asunción de algunas consideraciones próximas a la teoría deconstruccionista que propone de Man según las cuales hemos de contemplar que el desdoblamiento del yo enunciado en diversos yoes desemboca en la consideración del proceso autobiográfico como un artefacto retórico. Sidonie Smith se sitúa, pues, en un interesante término medio que tendremos muy en cuenta a la hora de estudiar el filme de Marazzi.

Era de esperar, de ahí el somero recorrido que hemos llevado a cabo por la teoría literaria, que buena parte de las consideraciones que se habían vertido sobre la autobiografía escrita se intentaran aplicar a los registros fílmicos que perseguían idénticas finalidades con las particularidades que el medio de expresión inevitablemente impone. Sin embargo, esta transposición presentaba sus dificultades, como ha puesto de manifiesto el teórico de referencia obligada en estas cuestiones, P. Lejeune, en un trabajo aparecido en el año 2008 donde se ocupa de este asunto. Desde su punto de vista se entiende por autobiografía un texto regido por un compromiso de veracidad que puede tener formas y funciones muy diferentes ligadas a la situación de escritura y al destino pero que, en cualquier caso, es íntimo por su contenido y público por su destino. Sin embargo, se pregunta, si "en el cine, el reparto entre íntimo, privado y público funcionará de la misma manera (¿se puede hacer una película con la idea de no enseñársela a nadie?)" (Lejeune, 2008: 17). Con estos presupuestos de partida, cabe contraponer dos posturas que se han mantenido hasta nuestros días: la de los teóricos que niegan la posibilidad de desarrollar la autobiografía dentro del séptimo arte fuera de los márgenes del cine de ficción y la de aquellos otros que, junto a los realizadores, están intentando demostrar lo contrario ${ }^{4}$.

De entre el primer grupo, es preciso destacar a Elizabeth W. Bruss (1980) cuya postura es considerada anticuada ya por Raymond Bellour en

\footnotetext{
${ }^{4}$ Los primeros pasos de este género, que Bela Bálázs consideraba que estaba llamado a equiparar en importancia a los diarios íntimos y autobiografías escritas, se dieron en el contexto artístico de las vanguardias como los autorretratos filmados de Man Ray, entre otros. Pero será, sobre todo a partir de los años 70 y asociado al fin de las grandes narraciones o metanarraciones que preconizaba Lyotard en La condición posmoderna cuando eclosione lo que Jean Pierre Chartier, en 1947, denominó "les films à la première personne". Precisamente en la década de los 80 , el documental autobiográfico experimenta un notable desarrollo de la mano de cineastas bien conocidos como Raymond Depardon, Alan Berliner o Ross McElwee que no hará sino crecer en los años siguientes hasta llegar a las cotas de finales de los 90 en las que se mantiene desde entonces con manifestaciones muy diversas y, a menudo, experimentales.
} 
L'entre-images: photo, cinema, vidéo (1990). Para la poeta estadounidense el cine, en cuanto medio de expresión, no puede proporcionar los tres parámetros que caracterizan a la autobiografía literaria clásica, a saber, el valor de verdad, el valor de acto y el valor de identidad. Estos tres requisitos, realmente constreñidos incluso para la literatura, se vuelven inviables en el cine toda vez que la concepción que Bruss tiene de las posibilidades que el séptimo arte puede proporcionar para el relato de la propia vida son inexistentes. En primer lugar, la estadounidense subraya el abismo que se abre entre la grabación de los acontecimientos "en bruto" y su reelaboración posterior en discurso fílmico. Este carácter implica, según ella, que el cineasta solo puede moverse entre dos posibilidades que son la verdad documental o el relato ficcional. La autobiografía fílmica no podría darse más que en forma ficcional, porque el documental está reservado para la recogida de datos objetivos y en ella no tendría cabida la subjetividad del cineasta. Condenado, pues, a la ficción, la autobiografía en el cine no sería tal pues no respondería al ineludible valor de verdad. Enlazado con este argumento estarían los otros dos que le siguen, a saber, el valor de acto y el valor de identidad. Y es que en la autobiografía fílmica se produce, necesariamente, una división de tareas, de manera que la fuente de discurso no sería en exclusiva el director del filme y, consecuentemente, este no podría aparecer revestido de la autoridad que precisa el autobiógrafo para contar su yo. A esto habría que sumar, según Bruss, que el lenguaje cinematográfico, por una parte, impide la identificación entre el yo que enuncia y ve y el que es visto y enunciado y, por otra parte, frente al lenguaje verbal que puede ser objetivo y subjetivo a la vez, el fílmico no admite esta simultaneidad.

Lejeune revisará los planteamientos unívocos de la crítica norteamericana y comenzará por oponerles algunas consideraciones incontestables entre las que vale mencionar el desarrollo que el cine autobiográfico tuvo después de la aparición del trabajo de Bruss o el uso de técnicas propias del registro fílmico, como la voz en off que permite recuperar parte de los beneficios del lenguaje verbal. Sin embargo, el francés se muestra siempre vacilante respecto a las posibilidades del cine para contar la propia vida pues, aunque es consciente y subraya la labor que los cineastas han llevado a cabo en el género en cuestión especialmente desde finales del siglo XX, se resiste a otorgar al séptimo arte las posibilidades que considera exclusivas de la literatura: 
El cine es, antes que nada, el lugar de la ficción. Nadie se acuerda de haber ido al cine a ver una autobiografia, stricto sensu. Tanto más, cuanto la imagen referencial, verídica, más bien sería para nosotros la imagen-televisión. Entre los géneros referenciales, el cine se presta mejor a la biografia que a la autobiografia (Lejeune, 2008: 21).

El problema que plantea la argumentación de Bruss, y más ambiguamente la de Lejeune, es que ambos vinculan la subjetividad, característica del género autobiográfico, al cine de ficción y la objetividad al documental como si no fuera posible el relato subjetivo en este último formato fílmico. Las razones que justifican sendos puntos de vista habría que buscarlas en la concepción que ambos estudiosos tienen del género autobiográfico literario, de su valor de verdad y de los mecanismos que rigen su composición y recepción. Sin entrar en estas cuestiones, que exceden con mucho los límites de este artículo, bastará con recordar, en palabras de Paola Lagos (2011: 65), que "el cine contemporáneo de no ficción ha demostrado claramente su radical divorcio de la pretendida objetividad atribuida casi por defecto al documental [...] y se ha decantado decididamente hacia la vocación subjetiva e introspectiva de las formas narrativas autobiográficas". De ello, además, dan buena cuenta trabajos de referencia obligada para ilustrar aquella vertiente teórica que defendía sin ambages la existencia de un cine autobiográfico de no ficción como Le je filmé de Y. Beauvais y J. M. Bouhours (1995), The Subject of Documentary de M. Renov (2004) o The Personal Camera: Subjective Cinema and the Essay Film de L. Rascaroli (2009).

Es posible afirmar que las películas de búsqueda identitaria en forma de documental son, como ocurre en los géneros del yo literarios en muchas ocasiones, de compleja categorización porque muchas de estas filmaciones, especialmente las construidas por cineastas mujeres, concitan en un solo discurso materiales de procedencia muy diversa visual y escrita ${ }^{5}$. Como recuerda E. Cuevas (2012: 107-108) sobre la múltiple

\footnotetext{
${ }^{5}$ Esta característica aparece con bastante frecuencia en los textos de carácter autobiográfico escritos por mujeres como hemos puesto de manifiesto en algunos trabajos como en "Dos autobiografías y una experiencia: María Teresa León y Rafael Alberti” (2004) o en el cuarto capítulo de El mundo narrativo de Elena Soriano (2007). Así, por ejemplo, Testimonio materno de Elena Soriano se
} 
temporalidad que puede darse en la autobiografía cinematográfica, en esta pueden coexistir imágenes y sonidos filmados en un tiempo concreto que pueden incluir situaciones cotidianas $\mathrm{u}$ otras menos improvisadas como las entrevistas, la música, los comentarios narratoriales, materiales escritos y audiovisuales recuperados del pasado, como fotos y películas caseras, etc.

Entre la diversidad de formas de contar la vida que ha desarrollado el documental autobiográfico en las últimas décadas nos interesa especialmente, en este trabajo, un tipo que fue bautizado por P. J. Eakin como proximate collaborative autobiography y que consistía en que:

The story of the self is constructed through the story told of ad by someone else. These collaborative texts feature two first-person speakers, the "I" of the proximate other's story and the "I" of what I term the story of the story, the narrative of the self's recording of the other's story. Because identity is conceived as relational in these instances, such narratives defy the distinctions we try to establish between genres, for they are autobiographies that offer not only the autobiography of the self but the biography and the autobiography of the other (Eakin, 1999: 176).

Este tipo de discurso autobiográfico creemos que es especialmente querido por las cineastas que no conciben la identidad más que de manera relacional. Como afirma Eakin, en estos casos, las fronteras genéricas, difíciles ya de por sí en los registros del yo, se hacen imposibles de establecer porque la autobiografía de una deviene discurso merced al relato de la biografía/autobiografía de otro u otra. El mismo título de la película de Alina Marazzi ya incluye el tú. Pasemos, pues, a recorrer este documental que bien puede colocarse bajo el marbete de auto-bio-grafía fílmica femenina.

construye como una autobiografía en tanto relata su experiencia desgraciada como madre pero también como una biografía de Juan José Arnedo puesto que, para reconstruir la etapa maternal de su vida, la autora necesita la figura del hijo. A esto añade numerosos fragmentos de un diario íntimo que vertebra buena parte de las más de 600 páginas que componen la obra. Estas tres modalidades de las llamadas escrituras biográficas que hemos mencionado están orquestadas por la cuarta y más importante variedad textual presente ya en el título, el testimonio. 


\section{UN'ORA SOLA TI VORREI: LA CARTA DE LUISELLA HOEPLI A ALINA MARAZZI}

Alina Marazzi (2002) escribe, en la edición en DVD del documental que vamos a analizar, lo siguiente:

Mia madre è nata nel 1938 ed è morta nel 1972, quando io avevo 7 anni. Non ho molti ricordi di lei, ma ho sempre saputo che in un armadio in casa dei miei nonni era rinchiusa tutta la memoria visiva della nostra famiglia. In questo armadio erano conservate delle scatole di vecchie pellicole, home movies girati del padre di mia madre tra il 1926 e gli anni '80, con una cinepresa amatoriale 16 $\mathrm{mm}$. Solo pochi anni fa ho avuto il coraggio di cominciare a guardare questi filmati, con grande curiosità ed emozione, soprattutto quelli segnati con una " $L$ ", l'iniziale del nome di mia madre: Liseli.

Come per magia, in un attimo, quella misteriosa e sconosciuta persona proiettata sullo schermo davanti a me era come se fosse viva. In un secondo ero catapultata nel passato, all'epoca in cui viveva una madre conosciuta poco e molto dimenticata.

El filme comienza con el registro sonoro de un disco de 45 r.p.m. con la voz de Liseli ${ }^{6}$ que le habla a su hija mientras se suceden las imágenes de una película casera donde se recoge una escena familiar intrascendente, un día de campo. Tras el rostro de la madre recién despierta, que mira interrogante la cámara que la graba (figura 2), aparece el de la realizadora, una niña que almuerza despreocupada con sus padres y su hermano Martino (figura 3).

${ }^{6}$ La madre de Alina Marazzi era llamada familiarmente Liseli. 

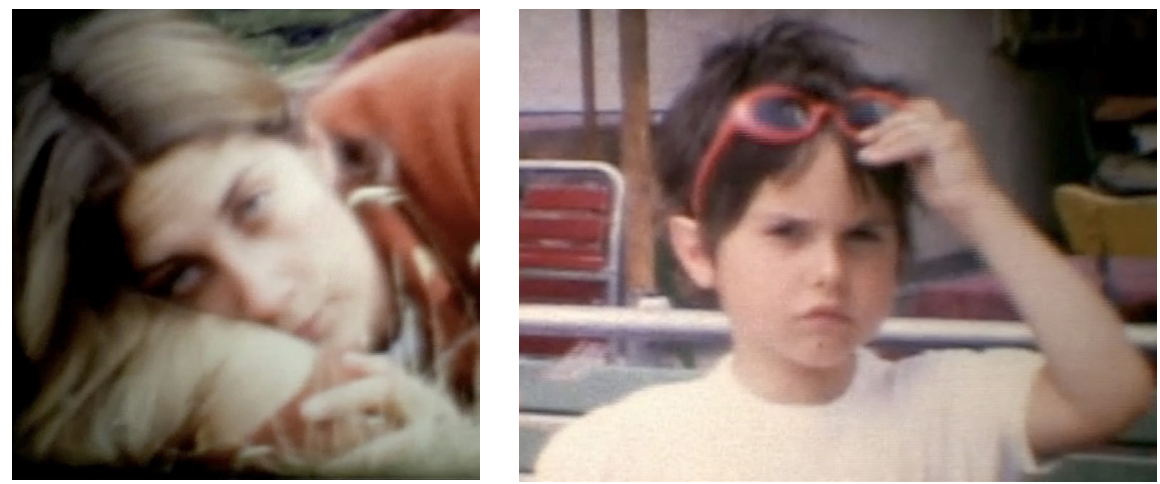

Figura 2. Liseli / Figura 3. Alina

Este par de minutos escasos, que actúan como prólogo de Un'ora sola ti vorrei, nos permite escuchar, entre otras voces, la de Luisella que comienza a cantar la canción que denomina el documental. Tras el título sobre impresionado en la pantalla mientras pasan las páginas de un diario manuscrito (figura 4), la voz alegre de Liseli da paso a la de Fedora Mingarelli que continua con la famosa composición italiana grabada en 1938 y cuya letra actúa como una declaración de intenciones, más aún, como una petición que Marazzi hace explícita para poder pasar "una hora más" con su madre que es precisamente lo que dura el filme.

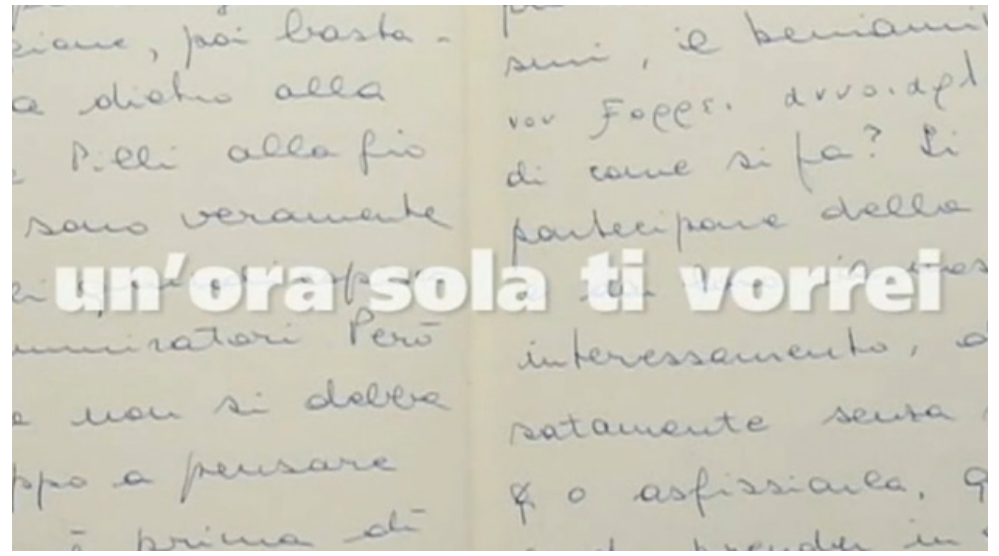

Figura 4. Un'ora sola ti vorrei 
Tras la imagen que se presenta arriba, el relato comienza, performativamente, con la voz over que Alina Marazzi le presta a su madre para que esta pueda contarle, en presente, como si de una carta se tratara, su historia, una historia silenciada por la familia que le ha sido sustraída a la hija huérfana desde los 7 años para quien nunca ha habido respuestas, hasta ahora:

Mia cara Alina, la voce che hai appena sentito che scherza, ride e che fa finta di sgridare te e Martino è la mia voce di 30 anni fa. [...] Nessuno ti ha parlato di me, di che ero, di come ho vissuto e di come me ne sono andata. Voglio raccontarti la mia storia, ora che è passato così tanto tempo da quando sono morta (Min. 2:13).

El documental se estructura como un discurso - voglio raccontarti - donde la cineasta actúa como destinataria del relato autobiográfico pero también como partícipe de él, construyendo así lo que P. J. Eakin había denominado proximate collaborative autobiography porque la identidad se concibe relacional. El punto de partida seleccionado es el día de la boda del hermano de Liseli, en 1965. La elección de ese año parece responder a la toma de conciencia por parte de la protagonista de una gran carencia íntima: "Già allora sapevo che non avrei trovato il mio posto nel mondo" (Min. 3:55).

Afirmar que existe un discurso autobiográfico propiamente femenino es aceptar el hecho de que la vida relatada desde la perspectiva de la mujer presenta unas marcas diferenciales temática y estructurales respecto a la vida narrada por el hombre. Entre estas marcas cabría destacar, como ya señaló Lydia Masanet (1988: 37), la descentralización del protagonista $\mathrm{y}$, en consecuencia, la importancia que cobra "lo demás" como un todo integrado en condiciones de igualdad con la enunciadora. Lógicamente este proceso de separación del relato autobiográfico androcéntrico no surge de la nada, sino que, en palabras de Sidonei Smith, “es paralela a la alteración de la tradición literaria masculina por el texto de la mujer. La mujer está inmersa en su subjetividad propia [...] e intentado, de este modo, representarse a sí misma" (1991: 94).

Efectivamente, Anna Caballé (1987: 103-110), al enumerar las figuras presentes en la autobiografía en general y, por lo tanto, mayoritariamente masculina, recoge aspectos como la importancia de los orígenes, 
el valor de los primeros recuerdos, la indisciplina escolar o la llamada del sexo, entre muchos otros. Por su parte, el discurso de la mujer se centra además, y sobre todo, en otros elementos semánticos relativos a los espacios personales e íntimos:

La autobiógrafa combina aspectos — descriptivos, impresionistas, dramáticos, analíticos - de la experiencia recordada, a medida que construye una narración que promete, a la vez, capturar los detalles de la experiencia personal y fundir su interpretación para la posteridad dentro de un molde intemporal e idealizado (Smith, 1991: 96).

Cuando la mujer comienza a relatar su vida busca descubrirse ante sí y ante los demás. Su objetivo, siguiendo a Lydia Masanet, es buscar las respuestas a los interrogantes que surgen en el transcurso de la escritura. Frente al proceso de narcisismo en el que parece estar interesada la narración autobiográfica tradicional, centrada en el embellecimiento y engrandecimiento del protagonista, el discurso femenino atiende fundamentalmente a la afirmación de la autenticidad de la propia imagen del yo, un yo privilegiado que no encaja con el resto de la clase mujer y que en el caso de la madre de Alina Marazzi es muy evidente y está declarado desde el principio del filme. A estos aspectos de contenido hemos de añadir la importancia concedida a los demás, por lo general seres queridos ${ }^{7}$, como elementos fundamentales en el proceso vital de la autobiógrafa.

Todos estos rasgos se organizan dentro de una estructura narrativa diferenciada cultivada por las autoras y que destaca por su carácter integrador, lo que lleva consigo, en la mayoría de los casos, unos mecanismos de composición singulares tales como la acumulación, la discontinuidad, la falta de linealidad temporal, la falta aparente de organización, la interrupción, la supresión, la repetición, etc.:

La discontinuidad en la estructura aparece como una herramienta

${ }^{7}$ Un ejemplo ilustrativo de esto que defendemos es que, para contar la vida de su madre, Alina Marazzi se remonta al noviazgo y boda de sus abuelos, los padres de Liseli, de los que se conservaron imágenes grabadas en películas caseras desde principios del siglo XX, en una cámara de aficionado de $16 \mathrm{~mm}$. 
apropiada al proyectar con más exactitud y veracidad la falta de linealidad en la existencia de la mujer. De esta forma es posible destacar los intereses multidimensionales que su identidad necesita y requiere. El plano semántico con el contenido de las experiencias, normalmente de carácter doloroso, se complementa con una estructura alineal que fomenta en su confluencia la unicidad del discurso autobiográfico en la mujer (Masanet, 1998: 38).

El relato de la vida de Luisella Hoepli comienza in medias res, ese día de 1965 mencionado donde ella declara tener conciencia de no haber encontrado su lugar en el mundo. Como cabía esperar, el discurso no responde a una linealidad temporal que avance del pasado hacia el presente sino que se sustenta sobre constantes movimientos analépticos y prolépticos donde, además, se concitan materiales de diversa naturaleza: cartas, diarios, fotografías, películas domésticas que dotan al conjunto de una enorme riqueza discursiva y plástica a la que contribuye decididamente el medio cinematográfico. Y es que no se debe perder de vista que el realizador ha de seleccionar los materiales de que dispone para llevar a cabo el montaje y tiene la posibilidad, como aprovecha Marazzi, de añadirle nuevas capas expresivas, la música, los sonidos descriptivos de las imágenes mudas, la voz over, etc. De esta manera el pasado resuena en el presente con modulaciones propias. Así lo explica la realizadora italiana:

Il resto del racconto intreccia la lettura di lettere e diari di mia madre e delle cartelle cliniche delle case di cura in cui mia madre ha trascorso lunghi periodi. Attraverso questi testi è possibile ricostruire per intero la sua vita, nei suoi vari periodi: l'adolescenza, l'amore, i figli, la malattia, il disagio esistenziale (Marazzi, 2002).

Un'ora sola ti vorrei se vertebra sobre un permanente e inquietante contraste entre las imágenes de felicidad de la alta burguesía italiana que recoge las películas caseras filmadas por el abuelo de Alina Marazzi y, por tanto, con una focalización androcéntrica ${ }^{8}$, y los textos sombríos que escri-

${ }^{8}$ Este punto de vista se hace evidente si nos percatamos de que el abuelo de Marazzi siempre filmó 
be Liseli y cuya lectura ilustra el visionado de las citadas imágenes. Así, por ejemplo, mientras contemplamos uno de los fotogramas de la boda de Luisella (figura 5) oímos los siguientes pensamientos transcritos en un diario:

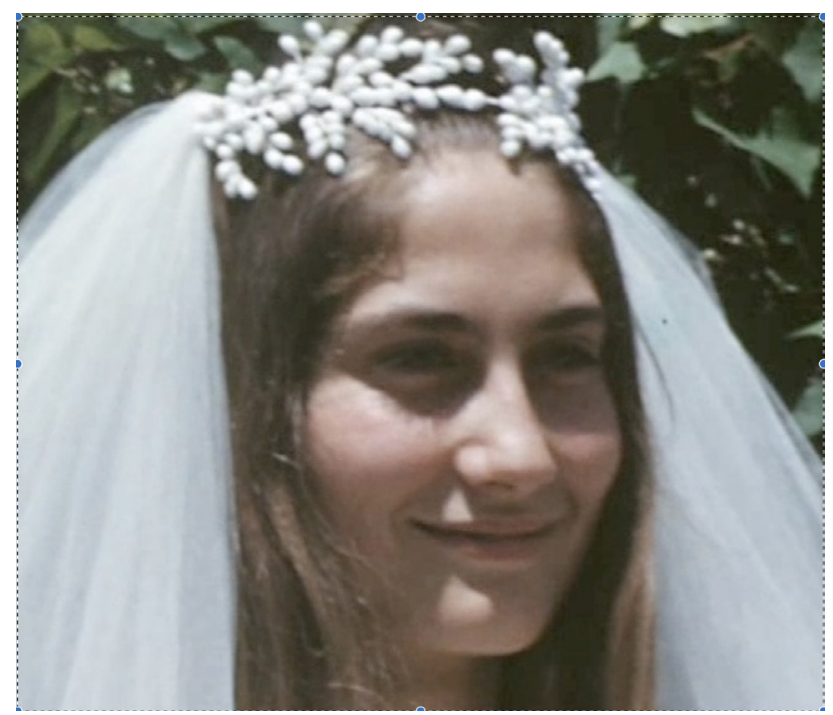

Figura 5. Boda de Liseli

Cosa posso dare ad Antonio io? Io ho tante esigenze. Non voglio la donna di servizio. Voglio che mi aiuti a lavare i piatti, a cambiare $i$ bambini. Sarei una selvaggia. Vorrei cucinasse solo per me, ma un uomo non si sottomette. Allora glio proporrei di essere la sua amante. Così quando vorrà un po' di vita selvaggia, verrà da me (Min. 28: 52).

Los estudios sobre el diario como género autobiográfico ponen de manifiesto que en él tiene cabida "casi todo", textos de diferente naturaleza que se integran para sustentar lo escrito, para ilustrarlo o simplemente por el apego a un elemento material en la medida en que lo consideramos

\footnotetext{
a su esposa y a su hija como objetos, hermosos y sonrientes. No captaba en ningún caso la mirada que estas mujeres le mandaban porque no las veía realmente. Las cartas y los diarios de Liseli cuestionan precisamente esta falsa felicidad.
} 
portador del poder preciso para trasladarnos a otro tiempo. Esta mezcolanza también se da en el documental que nos ocupa donde se alternan las lecturas de las entradas del diario de Liseli, los informes médicos de los sanatorios donde estuvo recluida o las cartas que escribió a otras mujeres fundamentales en su vida entre las que destaca su madre que, como acabamos de exponer, ilustran a contrario las imágenes. Estos textos, leídos por la voz de la directora, dan cuenta de la intimidad de Luisella Hopelli, como mujer, como hija, como madre, como amiga, como esposa, que no encaja con el resto de la clase mujer de su tiempo:

Siamo qui da 1 mese e la nostalgia mi strazia il cuore. Voi direte che sono la solita, che non so quello che voglio. Mi mancate molto e vi abbraccio tutti con tenero affetto, soprattutto tu, mamma, cui sono stata lontana in questi anni, e che ora vorrei avere vicino. Ed essere consolata come Martino vuole essere consolato da me. Mi sento ridicola, ma vorrei ese coccolata da te, mamma. Voglio dirti quanto mi facciano piacere le tue lettere. Ho capito che ancora me vuoi bene. Ero convita che fossi arrabbiata con me. Ma ora he capito che sono stupide idee. L'unico momento felice è quando vado a letto. Passo da momento di angoscia a momento di calma. Tutti guardano con sospetto a me a alla mia malattia, non considerandola tale.

El traslado a Estados Unidos marca definitivamente la vida de Liseli. Allí escribió la carta que acabamos de leer a la madre, donde son manifiestas su tristeza y su soledad y allí tuvo lugar su primer intento de suicidio, sus idas y venidas a distintas residencias mentales, hasta que, desgraciadamente, ella misma acabó con su vida en 1972. La lectura de los informes médicos nos habla de un estado depresivo y, de esta manera, se intenta si no justificar, sí explicar el comportamiento antinatura que supone poner fin a la propia vida.

En cualquier caso, lo que más nos interesa, llegados a este punto, es insistir en el modo en que la directora italiana ha articulado el relato de una vida íntima que no es la suya pero que le sirve para completar la propia. Así lo expresa la propia Marazzi:

Il film è la ricostruzioni della mia personale ricerca del volto di mia madre, attraverso il montaggio dei filmati girati da mio nonno. Per 
quasi tutta la mia vita il nome di mia madre è stato ignorato, evitato, nascosto. Il suo volvo anche. Ho la fortuna invece de poterla vedere muoversi, ridere, correre [...] Raccontare la storia di mia madre attraverso questi vecchi filmati è stato per mi ridare dignità al ricordo della persona che mi ha messo al mondo. E' un regalo che voglio fare a me (Marazzi, 2006).

La Librería de las Mujeres de Milán consideró Un’ora sola ti vorrei una muestra cinematográfica de restitución del orden simbólico de la madre. Y es que, como postula Milagros Rivera (1994: 200) se trata de reconocer la genealogía materna, cuya supresión implica la anulación de la subjetividad femenina, y la autoridad de las mujeres para entrar en el "orden simbólico de la madre" (Muraro, 1991). Si según la pensadora italiana la madre no solo es la portadora de la vida sino también de la lengua, la relación madre e hija se convierte en un lugar de enunciación (Rivera, 1994: 207) de este orden simbólico, como muestra el documental de Marazzi. A través de él, como la realizadora reconoce, no solo hay un intento de resolver la orfandad sino un profundo deseo de reconciliación y de compresión de la madre ausente. Como subraya Luciana Percovich (1996: 254-255) esta restitución del orden simbólico materno permite la conformación de la propia identidad y así Un'ora sola ti vorrei no solo es la recuperación de la memoria materna sino el alumbramiento de Alina Marazzi como creadora, como alguien con capacidad para nombrar el mundo en femenino. Una auto-bio-grafía, al fin.

La cineasta italiana opta, con coherencia, por leer una de las últimas entradas del diario de su madre, pocos días antes del suicidio, que está metaforizado visualmente con el fotograma donde se cierra el diario que inauguraba el documental. Seguidamente, a modo de síntesis, se suceden las imágenes de la protagonista, en orden cronológico inverso, mientras oímos, de nuevo, la auténtica voz de Luisella, la misma que abría el filme. De esta manera se dota a la película de una estructura circular, tan cultivada en el discurso de mujer, que imprime al conjunto la solidez y contundencia que necesita el relato que pretende a la par dignificar y reconstruir una vida al tiempo que da sentido a la propia. El resultado es de una extraordinaria belleza a la que colabora decididamente un diseño discursivo vertebrado en torno al reconocimiento de la autoridad materna (figura 6). 


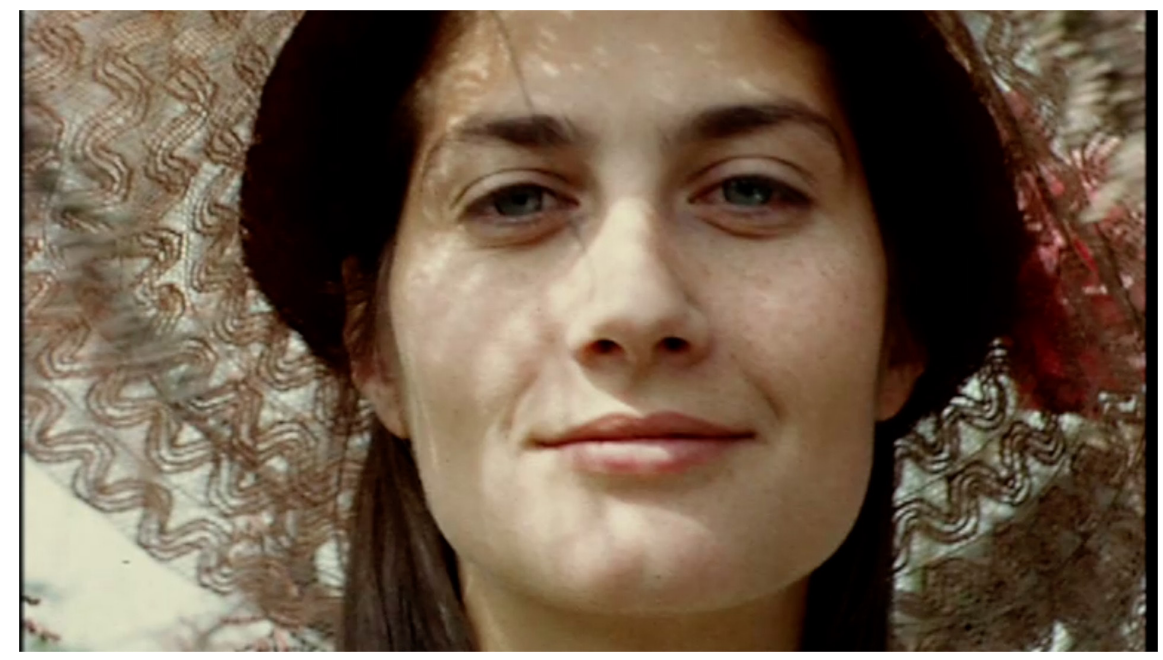

Figura 6. Luisella Hoepli, 1965.

\section{REFERENCIAS BIBLIOGRÁFICAS}

BEAUVAIS, Y. et BOUHOURS, J. M. (1995). Le jé filmé. Paris: Éditións du Centre Pompidou.

BELLOUR, R. (1990). L'entre-images: photo, cinema, video. Paris: La Différence.

BENSTOCK, S. (1988). "Authorizing the Autobiographical". En The Private Self. Theory and Practice of Women's Autobiographical Selves, S. Benstock (ed.), 10-33. Chapel Hill: University of North Carolina Press.

BRUSS, E. (1980). "Eye for I: Making and Unmaking Autobiography". En Autobiography: Essays Theoretical and Critical, J. Olney (ed.), 296-320. Princeton: Princeton UP.

CABALLÉ, A. (1987). "Figuras de la autobiografia". Revista de Occidente 73-75, 103-119.

CABO ASEGUINOZALA, F. (1993). "Autor y autobiografia". En Escritura autobiográfica, J. Romera Castillo, A. Yllera, M. GarcíaPage y R. Calvet (eds.), 131-138. Madrid: Visor. 
CASTILLA DEL PINO, C. (2004). "El eco autobiográfico". En Autobiografía en España: un balance, C. Fernández y M. Á. Hermosilla (eds.), 19-26. Madrid: Visor.

CATELLI, N. (1991). El espacio autobiográfico. Barcelona: Lumen.

CEPEDELLO MORENO, M. (2004). "Dos autobiografías y una experiencia: María Teresa León y Rafael Alberti”. En Autobiografía en España: un balance, C. Fernández y M. Á. Hermosilla (eds.), 361-372.

(2007). El mundo narrativo de Elena Soriano. Córdoba: Universidad de Córdoba / Ayuntamiento de Bujalance.

CHARTIER, J. P. (1947). "Les films à la première personne et l'illusion de réalité au cinéma”. La Revue du cinema 4, Janvier, 32-41.

CUEVAS, E. (2012). "El cine autobiográfico es España: una panorámica". Rilce 28.1, 106-125.

DE MAN, P. (1991). "La autobiografía como desfiguración”. Suplementos Anthropos 29, 113-118.

EAKIN, P. J. (1999). How Our Lives Become Stories: Making Selves. Ithaca: Cornell UP.

FRIEDMAN, S. (1988). "Women's Autobiographical Selves. Theory and Practice". En The Private Self. Theory and Practice of Women's Autobiographical Selves, S. Benstock (ed.), 34-62. Chapel Hill: University of North Carolina Press.

LAGOS LABBÉ, P. (2011). “Ecografías del 'Yo': documental autobiográfico y estrategias de (auto)representación de la subjetividad". Comunicación y medios 24, 60-80, (también en https://comunicacionymedios.uchile.cl/index.php/RCM/issue/ archive [05/04/2019]).

LEJEUNE, P. (1975). Le pacte autobiographique. Paris: Seuil.

(1980). Je est un autre. L'autobiographie, de la littérature aux médias. Paris: Seuil.

(1986). Moi aussi. Paris: Seuil.

(2001). "Definir la autobiografía". Boletín de la Unidad de Estudios Biográficos 5, 9-18.

(2004). "El pacto autobiográfico, 25 años después". En Autobiografía en España: un balance, C. Fernández y M. Á. Hermosilla (eds.), 159-172. Madrid: Visor Libros.

(2008). "Cine y autobiografía, problemas de vocabulario". En 
Cineastas frente al espejo, G. Martín Gutiérrez (coord.), 13-26. Madrid: T\&B.

(2015). Écrire sa vie: du pacte au patrimoine autobiographique. Paris: Éditions du Mauconduit.

LOUREIRO, Á. G. (1991). "Problemas teóricos de la autobiografía". Suplementos Anthropos 29, 2-8.

LYOTARD, J. F. (1984). La condición postmoderna: informe sobre el saber. Madrid: Cátedra.

MASANET, L. (1998). La autobiografía femenina española contemporánea. Madrid: Editorial Fundamentos.

MURARO, L. (1991). L'ordine simbolico della madre. Roma: Riuniti.

PERCOVICH, L. (1996). "Posiciones amorales y relaciones éticas". En Figuras de la madre, S. Tubert (ed.), 225-258. Madrid: Cátedra

RASCAROLI, L. (2009). The Personal Camera: Subjective Cinema and the Essay Film. London: Wallflower Press.

RENOV, M. (2004). The Subject of Documentary. Minneapolis: University of Minnesota Press.

RIVERA, M. (1994). Nombrar el mundo en femenino. Barcelona: Icaria.

SMITH, S. (1987). A Poetics of Women's Autobiography. Marginality and the Fiction of Self-Representation. Bloomington: Indiana University Press.

(1991). "Hacia una poética de la autobiografía de mujeres". Suplementos Anthropos 29, 93-105.

VILLANUEVA, D. (1993). "Realidad y ficción: la paradoja de la autobiografía”. En Escritura autobiográfica, J. Romera, A. Yllera, M. García-Page y R. Calvet (eds.), 15-32. Madrid: Visor Libros.

Recibido el 5 de abril de 2019.

Aceptado el 3 de junio de 2019. 